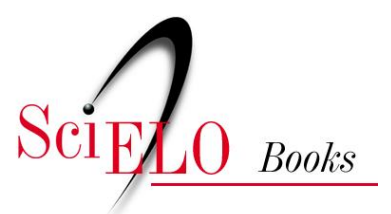

\title{
Ordem Ophidiiformes
}

\author{
Ana Cristina Teixeira Bonecker \\ Claudia Akemi Pereira Namiki \\ Márcia Salustiano de Castro \\ Paula Nepomuceno Campos
}

\section{SciELO Books / SciELO Livros / SciELO Libros}

BONECKER, ACT., et al. Ordem Ophidiiformes. In Catalogo dos estágios iniciais de desenvolvimento dos peixes da bacia de Campos [online]. Curitiba: Sociedade Brasileira de Zoologia, 2014, pp. 140-147. Zoologia: guias e manuais de identificação series. ISBN 978-85-98203-10-2.

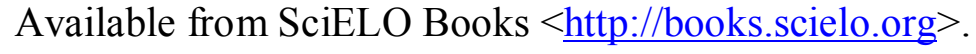

\section{(2)(1)(2)}

All the contents of this chapter, except where otherwise noted, is licensed under a Creative Commons Attribution-Non Commercial-ShareAlike 3.0 Unported.

Todo o conteúdo deste capítulo, exceto quando houver ressalva, é publicado sob a licença Creative Commons Atribuição Uso Não Comercial - Partilha nos Mesmos Termos 3.0 Não adaptada.

Todo el contenido de este capítulo, excepto donde se indique lo contrario, está bajo licencia de la licencia Creative Commons Reconocimento-NoComercial-CompartirIgual 3.0 Unported. 


\section{ORDEM OPHIDIIFORMES}

A ordem Ophidiiformes possui cinco famílias com aproximadamente 385 espécies. As nadadeiras pélvicas, quando presentes, estão inseridas ao nível do pré-opérculo ou muito antes, e a nadadeira caudal é confluente com as nadadeiras dorsal e anal.

Nesse estudo a ordem Ophidiiformes é representada pelas famílias Ophidiidae, Carapidae, e Aphyonidae. 


\section{Família Ophidiidae}

A família Ophidiidae é marinha e ocorre nos oceanos Atlântico, Índico e Pacífico. Compreende quatro subfamílias com 48 gêneros e aproximadamente 222 espécies. Os peixes desta família possuem a nadadeira dorsal igual ou mais longa que a nadadeira anal e as larvas não apresentam vexilo. Nesse estudo só foi registrada larva da subfamília Ophidiinae. Possuem corpo alongado e comprimento pré-anal relativamente curto. As nadadeiras dorsal e caudal são confluentes com a nadadeira caudal. O intestino forma uma volta na sua porção mediana ou final no início do desenvolvimento. As larvas mais desenvolvidas são lateralmente comprimidas. Os dois raios da nadadeira pélvica têm origem na região torácica e migram para a região posterior quando a larva assenta no fundo. Embora algumas espécies possam apresentar muitos pigmentos, as larvas da maioria das espécies são pouco pigmentadas.

No Brasil já foram identificadas 35 espécies nas fases de larva e adulto. Nesse estudo é contemplada a espécie Ophidion nocomis. 


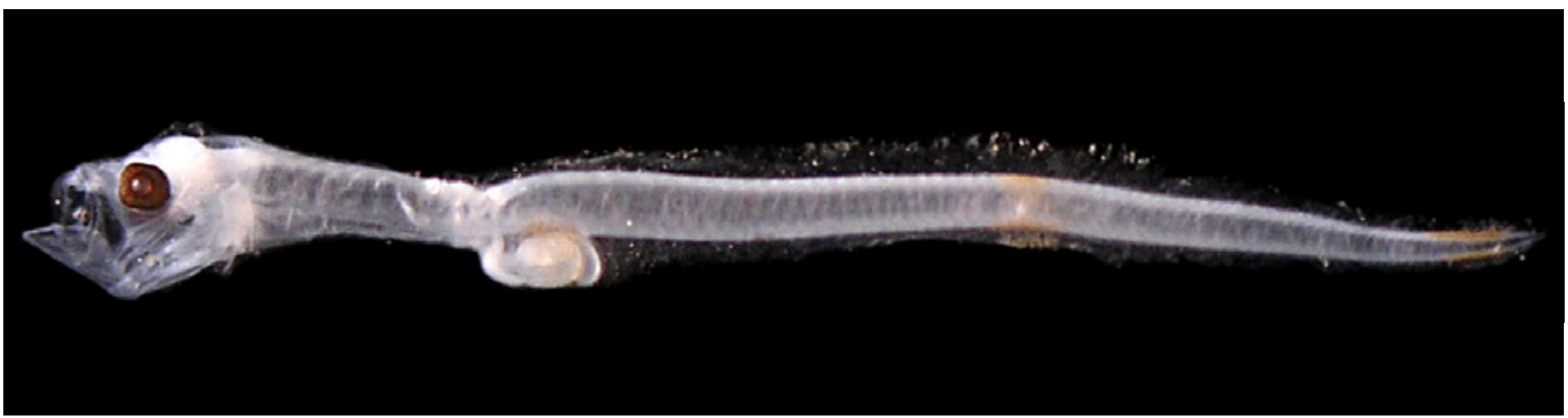

Figura 84: Ophidion nocomis. DZUFRJ 22406; Pré-flexão; CP 10,0 mm.

\section{Ophidion nocomis Robins \& Böhlke, 1959}

A cabeça e o corpo são extremamente delgados e o intestino forma uma volta próximo ao ânus. Esta região é muito pigmentada formando uma faixa. A região ventral do intestino não possui pigmentos. É observada uma faixa de pigmento no meio do corpo e outra na região do pedúnculo caudal. O número total de vértebras varia entre 84-87. Pode ser separada da espécie Ophidion selenops pelo padrão de pigmentação próximo ao ânus e na parte ventral do intestino que é mais intensa em 0 . nocomis.

Tamanho: pré-flexão 10,0 mm.

Habitat: espécie marinha, demersal, ocorre em águas tropicais até 17 $\mathrm{m}$ de profundidade.

\section{Georreferenciamento}

\begin{tabular}{|c|c|c|c|c|c|c|c|c|}
\hline DZUFRJ & Latitude (S) & Longitude (W) & Data & $\begin{array}{c}\text { Tipo de } \\
\text { arrasto }\end{array}$ & $\begin{array}{c}\text { Profundidade } \\
\text { de coleta }\end{array}$ & Rede & $\begin{array}{c}\text { Malha } \\
(\boldsymbol{\mu m})\end{array}$ & $\begin{array}{c}\mathbf{N}^{\circ} \text {. de } \\
\text { inds. }\end{array}$ \\
\hline 22406 & $22^{\circ} 399^{\prime} 68^{\prime}$ & $040^{\circ} 03,4^{\prime}$ & $13 / 06 / 2003$ & vertical & $0-60 \mathrm{~m}$ & cilíndrico-cônica & $500 \mu \mathrm{m}$ & 1 \\
\hline
\end{tabular}

Referências: Fahay \& Hare, 2006; Fahay, 2007. 


\section{Família Carapidae}

A família Carapidae é marinha e ocorre nos oceanos Atlântico, Índico e Pacífico. Compreende sete gêneros e 31 espécies. Algumas espécies são mesopelágicas e outras demersais vivendo como inquilinas nas cavidades de invertebrados, como bivalves, holotúrias e asteroides. Carapus bermudensis, vive em associação com pepinos do mar enquanto Echiodon dawsoni e Snyderidia canina são de vida livre. As larvas planctônicas possuem um filamento pré-dorsal longo e normalmente ornamentado, denominado vexilo. Esta estrutura aparentemente representa uma especialização das larvas desta família. O corpo é alongado e as nadadeiras dorsal e anal são longas.

No Brasil já foram identificadas quatro espécies nas fases de larva e adulto: Carapus bermudensis (Jones, 1874); Echiodon cryomargarites Markle, Williams \& Olney, 1983; Echiodon dawsoni Williams \& Shipp, 1982 e Snyderidia canina Gilbert, 1905. Nesse estudo são contempladas as espécies Echiodon dawsoni e Snyderidia canina. 


\section{Echiodon dawsoni} Williams \& Shipp, 1928

O corpo é alongado com cauda filamentosa. O número de vértebras pré-caudais varia entre 21-25. O vexilo está localizado na altura do miômero 11, posterior a origem da nadadeira anal, e apresenta poucas ornamentações. 0 primeiro raio da nadadeira dorsal se insere imediatamente após o vexilo. Possui entre nove e treze raios na nadadeira anal anteriores à origem da nadadeira dorsal. Ausência de nadadeiras pélvicas e as peitorais têm bases lobadas. A região peritoneal é muito pigmentada.

Tamanho: 3,0- > 75,0 mm.

Habitat: espécie marinha, demersal, ocorre águas tropicais em profundidades entre 75 e $175 \mathrm{~m}$.

\section{Georreferenciamento}

\begin{tabular}{|c|c|c|c|c|c|c|c|c|}
\hline DZUFRJ & Latitude (S) & Longitude (W) & Data & $\begin{array}{c}\text { Tipo de } \\
\text { arrasto }\end{array}$ & $\begin{array}{c}\text { Profundidade } \\
\text { de coleta }\end{array}$ & Rede & $\begin{array}{c}\text { Malha } \\
\mathbf{( \mu m )}\end{array}$ & $\begin{array}{c}\mathbf{N} \text {. de } \\
\text { inds. }\end{array}$ \\
\hline 520 & $22^{\circ} 34^{\prime} 05,0^{\prime \prime}$ & $040^{\circ} 19^{\prime} 40,0^{\prime \prime}$ & $17 / 05 / 2002$ & oblíquo & $600 \mathrm{~m}$ & cilíndrico-cônica & 500 & 3 \\
\hline 652 & $22^{\circ} 38^{\prime} 25,0^{\prime \prime}$ & $040^{\circ} 17^{\prime} 41,0^{\prime \prime}$ & $19 / 05 / 2002$ & oblíquo & $40 \mathrm{~m}$ & bongô & 330 & 1 \\
\hline 5422 & $22^{\circ} 31^{\prime} 58,9^{\prime \prime}$ & $040^{\circ} 02^{\prime} 53,4^{\prime \prime}$ & $07 / 11 / 2001$ & oblíquo & $1.000 \mathrm{~m}$ & cilíndrico-cônica & 500 & 1 \\
\hline 7526 & $21^{\circ} 58^{\prime} 31,0^{\prime \prime}$ & $039^{\circ} 50^{\prime} 29,7^{\prime \prime}$ & $10 / 10 / 2001$ & oblíquo & $1.000 \mathrm{~m}$ & cilíndrico-cônica & 500 & 1 \\
\hline 7527 & $21^{\circ} 54^{\prime} 36,5^{\prime \prime}$ & $039^{\circ} 45^{\prime} 20,0^{\prime \prime}$ & $10 / 10 / 2001$ & oblíquo & $1.000 \mathrm{~m}$ & cilíndrico-cônica & 500 & 1 \\
\hline
\end{tabular}

Referências: Markle \& Olney, 1990; Namiki \& Bonecker, 2006; Olney, 2006b; Namiki et al., 2007b; Fahay, 2007.

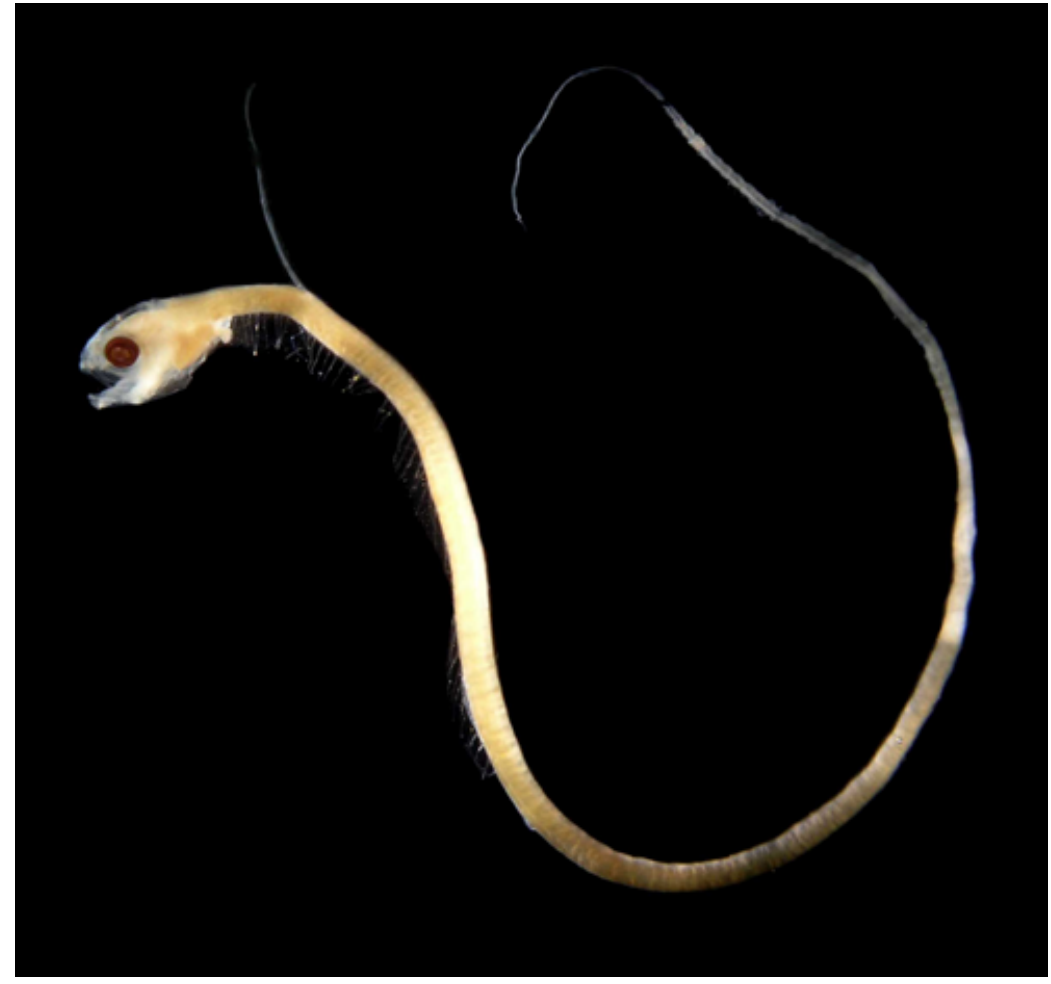

Figura 85 - A: Echiodon dawsoni. DZUFRJ 7526; CP >75,0 mm;

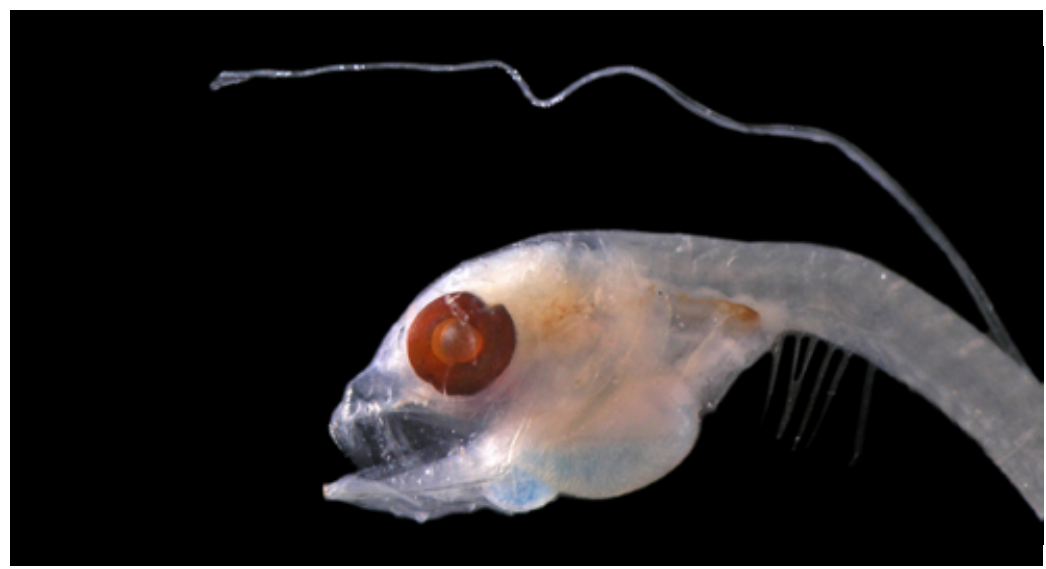

Figura 85 - B: Detalhe da cabeça. 


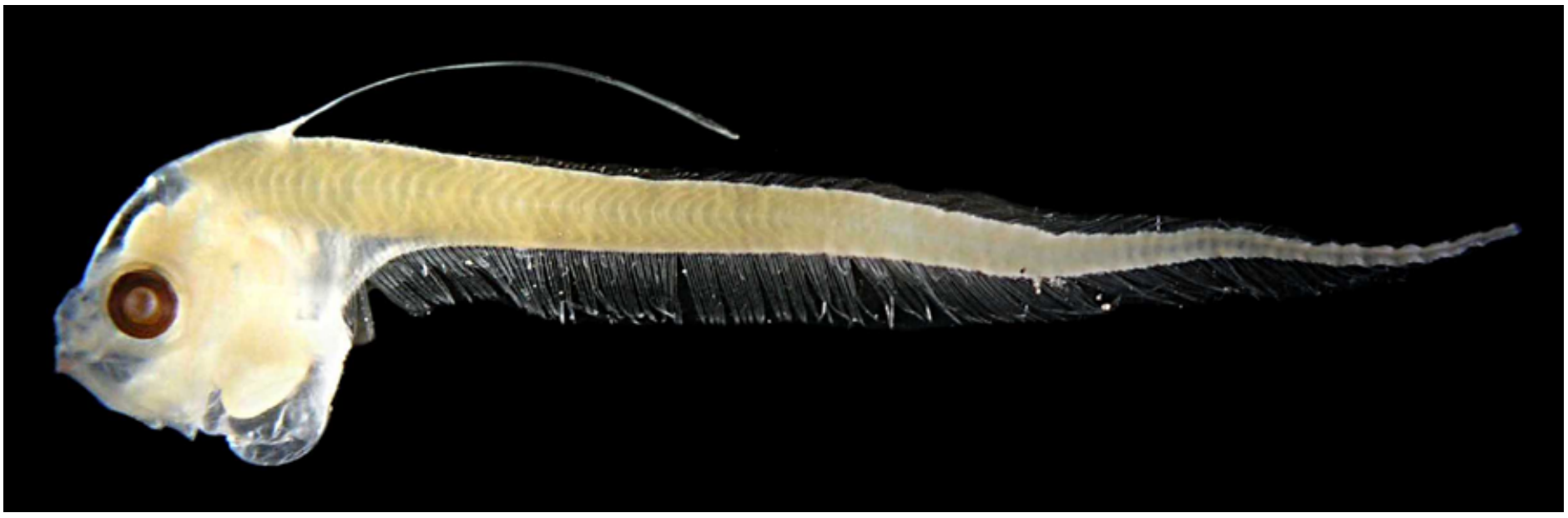

Figura 86: Snyderidia canina. DZUFRJ 5421; CP 26,5 mm.

\section{Snyderidia canina Gilbert, 1905}

O corpo não é tão alongado quando comparado com outras espécies de Carapidae. O número de vértebras pré-caudal varia entre 13-15. A cabeça é grande e o corpo é alto. O vexilo não possui ornamentação e é adjacente ao primeiro raio da nadadeira dorsal. Possui entre seis e nove raios dorsais anteriores à origem da nadadeira anal. Apresenta pigmentos na sínfise da maxila inferior e internamente na região da vesícula gasosa. Não possui dentes cardiformes nem nadadeira pélvica.

Tamanho: $26,5 \mathrm{~mm}$.

Habitat: espécie marinha, mesopelágica, ocorre em águas tropicais entre 110 e $1.500 \mathrm{~m}$ de profundidade.

\section{Georreferenciamento}

\begin{tabular}{|c|c|c|c|c|c|c|c|c|}
\hline DZUFRJ & Latitude (S) & Longitude (W) & Data & $\begin{array}{c}\text { Tipo de } \\
\text { arrasto }\end{array}$ & $\begin{array}{c}\text { Profundidade } \\
\text { de coleta }\end{array}$ & Rede & $\begin{array}{c}\text { Malha } \\
\text { ( } \boldsymbol{\mu m} \text { ) }\end{array}$ & $\begin{array}{c}\mathbf{N}^{\circ} \text {. de } \\
\text { inds. }\end{array}$ \\
\hline 5421 & $22^{\circ} 32^{\prime} 50,0^{\prime \prime}$ & $040^{\circ} 04^{\prime} 09,9^{\prime \prime}$ & $06 / 11 / 2001$ & oblíquo & $1.000 \mathrm{~m}$ & cilíndrico-cônica & 500 & 1 \\
\hline
\end{tabular}

Referências: Markle \& Olney, 1990; Olney, 2006b; Namiki et al., 2007b; Fahay, 2007. 


\section{Família Aphyonidae}

A família Aphyonidae é marinha e ocorre nos oceanos Atlântico, Índico e Pacífico. Compreende seis gêneros e 22 espécies. As larvas são raras e não há descrição para as larvas do Oceano Atlântico.

No Brasil já foram identificadas as espécies Aphyonus gelatinosus Günther, 1878 e Barathronus bicolor Goode \& Bean, 1886. Na área de estudo é contemplada o morfotipo Aphyonidae sp. 1. 


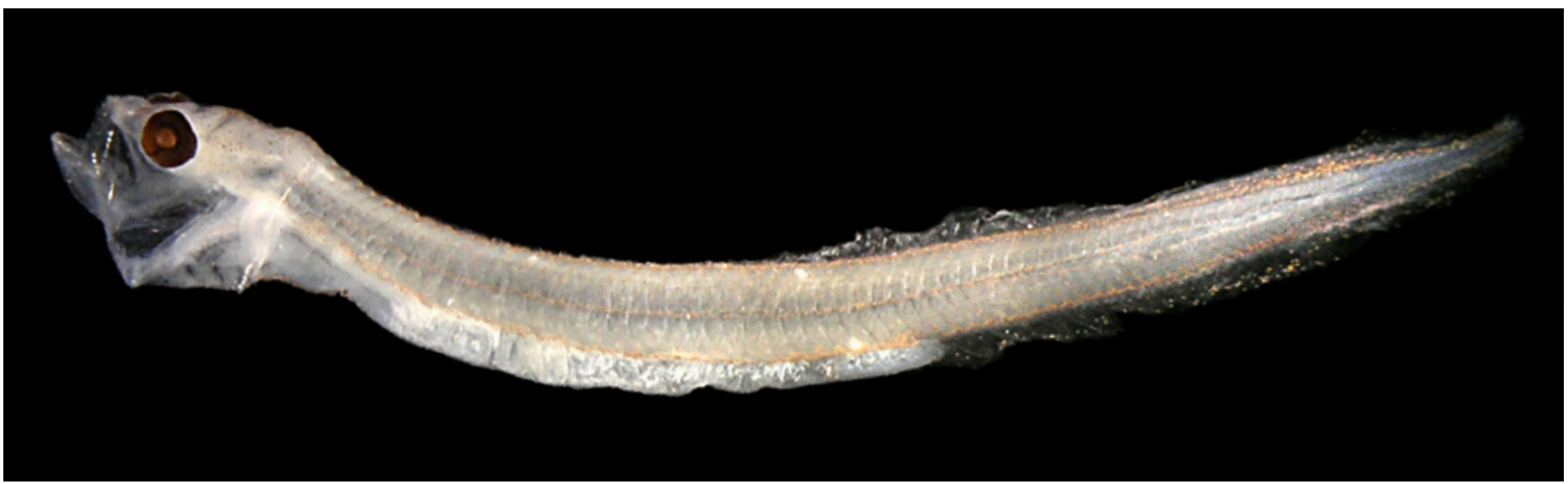

Figura 87: Aphyonidae sp. 1. DZUFRJ 22410; Flexão; CP 9,6 mm.

\section{Aphyonidae sp. 1}

Possui intestino longo e estreito. As nadadeiras dorsal e anal são confluentes. Os olhos são pouco desenvolvidos. O número de vértebras pré-caudais varia entre $26-48$ e o número total entre 68-86. O exemplar coletado na área de estudo apresenta a origem da nadadeira dorsal muito atrás da nadadeira peitoral.

Tamanho: pré-flexão 9,6 mm.

Habitat: todas as espécies são marinhas e podem ocorrer em profundidades superiores a $700 \mathrm{~m}$.

\section{Georreferenciamento}

\begin{tabular}{|c|c|c|c|c|c|c|c|c|}
\hline DZUFRJ & Latitude (S) & Longitude (W) & Data & $\begin{array}{c}\text { Tipo de } \\
\text { arrasto }\end{array}$ & $\begin{array}{c}\text { Profundidade } \\
\text { de coleta }\end{array}$ & Rede & $\begin{array}{c}\text { Malha } \\
(\boldsymbol{\mu m})\end{array}$ & $\begin{array}{c}\mathbf{N}^{\circ} \text {. de } \\
\text { inds. }\end{array}$ \\
\hline 22410 & $22^{\circ} 03^{\prime} 033^{\prime \prime}$ & $039^{\circ} 50^{\prime} 39,0^{\prime \prime}$ & $10 / 05 / 2002$ & horizontal & superfície & cilíndrico-cônica & 200 & 1 \\
\hline
\end{tabular}

Referências: Menezes et al., 2003; Fahay \& Hare, 2006; Nelson, 2006; Fahay, 2007; Franco et al., 2007; Mincarone et al., 2008; Froese \& Pauli, 2014. 